\title{
Prognostic Factors in Oligodendroglioma
}

\author{
D. Schiffer, A. Dutto, P. Cavalla, I. Bosone, A. Chiò, R. Villani and C. Bellotti
}

\begin{abstract}
Background: A reliable marker for tumor oligodendroglial cells is not yet available, so that the histological recognition of the tumor still encounters uncertainties. There is no general agreement also on prognostic factors in oligodendroglioma. The inconsistency concerns mainly the histopathological factors. The aim of the study was recognition of prognostic factors in oligodendroglioma. Methods: In a series of ninety-eight oligodendrogliomas, including twenty mixed oligoastrocytomas, clinical [sex, age at surgery, tumor location, symptoms at presentation], therapeutic [extent of resection, year of surgery, post-operative Karnofsky score, post-operative radiotherapy, post-operative chemotherapy], histological [cell density, nuclear pleomorphism, vascular endothelial proliferation, necrosis, microcysts, mitoses, mitotic index (MI), apoptosis, apoptotic index (AI)] and immunohistochemical parameters [MIB-1 and PCNA Labeling Indexes (LIs), staining for GFAP, positivity for p53] were correlated with survival in uni- and multivariate analysis in order to identify their prognostic significance. Results: Age at surgery, extent of surgical resection, year of surgery, postoperative Karnofsky score and MIB-1 LI were associated with survival in both uni- and multivariate analysis. Location, symptoms at presentation, mitoses, MI, AI, and PCNA LI showed a significant correlation with survival in uni- but not in multivariate analysis. The twenty cases of oligoastrocytomas did not show any difference in survival from pure oligodendrogliomas. Conclusions: Some clinical and therapeutic factors together with MIB-1 LI play a prognostic role. MIB-1 LI is prognostic with a cutoff of $8 \%$. Histology gives a limited contribution to the prognosis. Oligoastrocytomas had the same outcome and prognostic factors as pure oligodendrogliomas.
\end{abstract}

\begin{abstract}
RÉSUMÉ: Les facteurs pronostiques dans l'oligodendrogliome. Introduction: Il n'y a pas de marqueur spécifique pour les cellules tumorales de source oligodendrogliale, ce qui cause de l'incertitude dans l'identification histologique de cette tumeur. Il n'y a pas de consensus au sujet des facteurs pronostiques et les facteurs histopathologiques n'ont pas été complètement identifiés. Le but de cette étude était d'identifier les facteurs pronostiques de l'oligodendrogliome. Méthodes: Dans une série de 98 oligodendrogliomes, incluant 20 oligoastrocytomes, les paramètres cliniques (sexe, âge à l'opération, localisation de la tumeur, symptômes initiaux), thérapeutiques (étendue de la résection, année de l'opération, score de Karnofsky postopératoire, radiothérapie postopératoire, chimiothérapie postopératoire), histologiques [densité cellulaire, polymorphisme nucléaire, prolifération vasculaire endothéliale, nécrose, microkystes, mitoses, indice mitotique (MI), apoptose et indice apoptotique (IA)] et immunohistochimiques [indice de marquage MIB-1 et PCNA (IM), positivité pour GFAP et p53] ont été corrélés avec la survie par analyse uni et multivariée, pour identifier leur signification pronostique. Résultats: L'âge à l'opération, l'extension de la résection chirurgicale, l'année de l'opération, le score de Karnofsky postopératoire et le MI MIB-1 étaient associés avec la survie dans l'analyse tant univariée que multivariée. L'analyse univariée, mais non l'analyse multivariée, montrait une corrélation de la localisation de la tumeur, des symptômes initiaux, des mitoses, du MI, de l'IA et de l'IM PCNA avec la survie. Les 20 cas d'oligoastrocytomes ne montraient aucune différence quant à la survie par rapport aux oligodendrogliomes pures. Conclusions: Des facteurs cliniques et thérapeutiques ainsi que l'IM MIB-1 jouent un rôle pronostique. L'IM MIB-1 est pronostique avec un point de coupe à $8 \%$. La contribution de l'histologie au pronostic est limitée. Les oligoastrocytomes avaient la même issue et les mêmes facteurs pronostiques que les oligodendrogliomes pures.
\end{abstract}

Can. J. Neurol. Sci. 1997; 24: 313-319

Oligodendrogliomas appear histologically as rather homogeneous tumors but, in practice, their nosographic delimitation is not easy and their frequency greatly varies in the different series: $18.8 \%^{1}$ and $5 \% .^{2}$ Furthermore, their prognosis is not yet completely defined, because there is no general agreement in the literature on the prognostic significance of several factors. The evaluation of new chemotherapeutic associations ${ }^{3-6}$ requires a better knowledge of the prognosis. The application of histologi- cal grading systems has led to contrasting results. In some series three grades ${ }^{7-9}$ and in other series only two grades ${ }^{10}$ have been

From the Department of Neuroscience, University of Turin, Turin, Italy; Institute of Neurosurgery, University of Milan, Milan, Italy (R.V.); Division of Neurosurgery, Ospedale Maggiore, Novara, Italy (C.B.)

RECEIVED JANUARY 30, 1997. ACCEPTED IN FINAL FORM MAY 12, 1997.

Reprint requests to: D. Schiffer, Division of Neurology, Department of Neuroscience, via Cherasco, 15, 10126 Turin, Italy 
prognostically useful. Among histological features, necrosis has emerged as a more constant prognostic factor than mitoses. ${ }^{11,12}$ Tumor location appears to be a prognostic factor, ${ }^{9}$ as well as the extent of surgical removal. ${ }^{10,13}$ More recently, MIB-1 and PCNA labeling indexes (LIs) have been identified as useful prognostic factors. $9,14,15$ The problem is complicated by the recognition of oligoastrocytoma as a tumor entity by the WHO Classification. ${ }^{16}$ In previous investigations, some large oligodendroglioma series included oligoastrocytomas ${ }^{4,7,13,18}$ while other series kept them separated $9.10,15,17,19$ for prognostic evaluation. In the present paper, the results of a study of ninety-eight oligodendrogliomas, including twenty oligoastrocytomas, are presented: prognostic factors are identified among different clinical, therapeutic, histological and immunohistochemical variables.

\section{Materials and Methods}

One hundred and thirty-six cases of supratentorial oligodendroglioma, consecutively operated in the Departments of Neurosurgery of the Universities of Turin, Milan and Novara (Italy) from 1960 to 1992 , were studied. Fifteen patients lost to follow-up and ten patients who died within 30 days of surgery were excluded from survival analysis. Thirteen patients who underwent biopsy only were excluded, since the histopathological parameters were not reliable in these cases. Ninety-eight cases were thus eligible for analysis of prognostic factors. The series included twenty cases of mixed oligoastrocytoma.

\section{Patient Population}

Fifty-six cases were male (57\%) and forty-two female (43\%). The age at surgery ranged from 18 to 69 years (mean, $45 \mathrm{ys}$ ). Thirty-six patients underwent early post-operative radiotherapy (doses $>40 \mathrm{~Gy}$ ), six of which also underwent chemotherapy. One patient had chemotherapy only.

\section{Pathology}

Surgical specimens were fixed in Carnoy or formalin and embedded in paraffin. Five-micron thick sections were cut and stained by hematoxylin-eosin $(\mathrm{H} \& \mathrm{E})$. All specimens were histologically reviewed in a blinded fashion and categorized by two of us (D. S. and A. D.). The degree of concordance was $>90 \%$. The grading system of the St. Anne-Mayo ${ }^{20}$ was used.

\section{Factors Examined}

For each patient, clinical, therapeutic, histological and immunohistochemical parameters were considered.

Clinical Parameters: 1) sex; 2) age at surgery; 3) tumor location; 4) symptoms at presentation (headache, partial or generalized seizures, focal neurologic deficits, intracranial hypertension or two or more of the previous symptoms).

Therapeutic Parameters: 1) extent of surgical resection (total or partial); 2) year of surgery (before 1970, 1970-1980 or after 1980); 3) post-operative Karnofsky score; 4) post-operative radiotherapy (yes or no); 5) post-operative chemotherapy (yes or no).

The extent of surgical resection was determined solely from the operative reports. No consideration was given to post-operative imaging studies.

Histological parameters, studied on H\&E stained sections: 1) cell density ( $<90$ vs. $\geq 90$ cells by high power field, HPF, at $1000 \mathrm{x}$ ); 2) nuclear pleomorphism (present or absent); 3) vascular endothelial proliferation (absent, moderate or abundant); 4) necrosis (present or absent); 5) microcysts (present or absent); 6) mitoses (present or absent) and mitotic index (MI); 7) apoptosis (present or absent) and apoptotic index (AI). Apoptotic nuclei were recognized by the aspect of their chromatin and by the insitu end-labeling (ISEL) of DNA breaks by terminal deoxynucleotidyl transferase (TdT) and digoxigenin-11-dUTP.21

Immunohistochemical Parameters: 1) staining for GFAP; 2) LI for MIB-1 and PCNA; 3) positivity for p53.

GFAP immunostaining was detected by GFAP monoclonal antibody (MAb), clone 6F2 (Dako), diluted 1:100. MIB-1 immunostaining was detected by $\mathrm{Ki}-67 \mathrm{MAb}$, clone MIB-1 (AMAC Inc.), diluted 1:100. PCNA immunostaining was detected by PCNA MAb, clone PC 10 (Dako), diluted 1:300. p53 protein accumulation was detected by p53 MAb, clone DO1 (Oncogene Sci.), diluted 1:100. The immune reactions were revealed by Strept-ABC and by diaminobenzidine as a chromogen. Light counterstaining was performed with hematoxylin. For MIB-1 dewaxed sections were immersed in citrate buffer and processed in a microwave oven (Whirlpool) at 750 Watt, $5 \mathrm{x}$ 3 minutes.

The cases with gliofibrillary oligodendrocytes (GFOC) and/or minigemistocytes (MG) expressing GFAP, ${ }^{22}$ independently of the extension of their distribution, were considered GFAP-positive oligodendrogliomas. Reactive astrocytes were not considered, whereas tumor astrocytes and regular gemistocytes, either in small or wide areas or interspersed in the tumor, were considered as the astrocytic componenent of a mixed oligoastrocytoma.

AI, MI and LI for MIB-1 and PCNA were calculated as percentages, by counting at least $10 \mathrm{HPF}$ at $1000 \times\left(0.02 \mathrm{~mm}^{2}\right)$ and not less than 1000 cells. AI, MI and LI of each tumor were those corresponding to the areas with the highest values. PCNA LI was calculated after counting only very intensely positive nuclei, more probably corresponding to the $S$ phase. ${ }^{23}$ Therefore, PCNA LIs were usually lower than MIB-1 LIs. The analysis of PCNA and MIB-1 LIs was performed in 71 cases. p53 immunostaining was categorized as present or absent.

\section{Statistical Analysis}

Actuarial survival curves were generated by using the Kaplan-Meier method ${ }^{24}$ with death as end point. For numerically continuous variables (age, Karnofsky score, MI, AI, PCNA LI and MIB-1 LI) the cut-off point which best subdivided patients into distinct survival groups was searched, according to Segal. ${ }^{25}$ The relationship between each parameter and survival was examined in a series of univariate analyses performed using a log-Rank test. ${ }^{26}$ Cox regression analysis with multiple independent variables was then employed to identify parameters that were independently predictive of survival. ${ }^{27} \mathrm{p}$ values (2-sides) $\leq 0.05$ were considered to be significant.

\section{Results}

\section{Survival}

Post-operative mean and median survival times were $66( \pm 6)$ months and 51.6 months respectively. The overall 5- and 10year survival rates were $40 \%$ and $14 \%$ respectively. At the time of the analysis twenty patients $(20 \%)$ were still alive. 


\section{Univariate and Multivariate Survival Analysis}

Univariate analysis was performed in order to establish the correlation between each parameter and survival (Table 1). The following clinical and therapeutic parameters resulted significantly correlated with survival: age (Figure 1), tumor location, symptoms at presentation (Figure 2), extent of surgical resection (Figure 3), period of surgery performance (Figure 4), post-operative Karnofsky score (Figure 5).

Table 1: Statistical Correlation Between Each Parameter Studied and Survival in Univariate Analysis.

\begin{tabular}{|c|c|}
\hline FACTORS EXAMINED & p value \\
\hline sex & n.s. \\
\hline age at surgery $(<30$ vs. $30-50$ vs. $>50)$ & $p=0.0003$ \\
\hline tumor location (frontal vs. others) & $\mathrm{p}=0.02$ \\
\hline symptoms at presentation (headache vs. partial seizures & $\mathrm{p}=0.005$ \\
\hline \multirow{2}{*}{\multicolumn{2}{|c|}{$\begin{array}{l}\text { vs. generalized seizures vs. focal neurologic deficits vs. } \\
\text { intracranial hypertension vs. two of previous symptoms or more) }\end{array}$}} \\
\hline & \\
\hline extent of resection (total vs. partial) & $p=0.03$ \\
\hline year of surgery (before $1970 \mathrm{vs.} 1970-1980 \mathrm{vs.} \mathrm{after} \mathrm{1980)}$ & $\mathrm{p}=0.008$ \\
\hline post-operative Karnofsky score ( $\leq 60$ vs. $70-80$ vs. $\geq 90$ ) & $\mathrm{p}=0.0001$ \\
\hline post-operative radiotherapy (yes vs. no) & n.s. \\
\hline post-operative chemotherapy (yes vs. no) & n.s. \\
\hline grading according to St. Anne-Mayo system & n.s. \\
\hline cell density ( $<90$ vs. $\geq 90$ cells by HPF at $1000 x)$ & n.s. \\
\hline nuclear pleomorphism (present vs. absent) & n.s. \\
\hline vascular endothelial proliferation (absent vs. moderate vs. abundant) & n.s. \\
\hline necrosis (present vs. absent) & n.s. \\
\hline microcysts (present vs. absent) & n.s. \\
\hline mitoses (present vs. absent) & $p=0.04$ \\
\hline mitotic index (MI <0.2\% vs. $\geq 0.2 \%)$ & $\mathrm{p}=0.02$ \\
\hline apoptosis (present vs. absent) & n.s. \\
\hline apoptotic index ( $\mathrm{AI}<0.05 \%$ vs. $\geq 0.05 \%$ ) & $p=0.05$ \\
\hline immunostaining for GFAP & n.s. \\
\hline MIB-1 LI (MIB-1 LI < 8\% vs. $\geq 8 \%$ ) & $p=0.02$ \\
\hline PCNA LI (PCNA LI < $3.5 \%$ vs. $\geq 3.5 \%$ ) & $\mathrm{p}=0.02$ \\
\hline positivity for p 53 (present vs. absent) & n.s. \\
\hline
\end{tabular}

Effects of histologic grades on survival: no statistical correlation was found between tumor grades, according to the St. Anne-Mayo grading system, and survival $(p=0.24)$ (Figure 6). Also grouping together grade 1-2 and grade 3-4 no correlation was found. A trend towards a shorter survival was found for tumors of grade 4 compared with the tumors of grades 1-2-3 grouped together. The median survival time of the first group was 28 months versus 58 months of the second group $(p=0.06)$. The presence of mitoses correlated with a shorter survival $(p=$ $0.04)$. Tumors with $M I \geq 0.2 \%(n=48)$ had a median survival time of 28 months, compared with 74 months for tumors with MI $<0.2 \%(\mathrm{n}=50)(\mathrm{p}=0.02)$. The occurrence of apoptosis (Figure 7a) did not correlate with survival, while AI did. Tumors with $\mathrm{AI} \geq 0.05 \%(\mathrm{n}=36)$ had a median survival time of 28 months, compared with 58 months of tumors with $\mathrm{AI}<0.05 \%$ $(n=62)(p=0.05)$. Other histological parameters did not significantly correlate with survival. Correlation of proliferation markers with survival: the median survival time of the 36 cases with MIB-1 LI $\geq 8 \%$ was 26 months versus 80 months of the 35 cases with MIB-1 LI $<8 \%(\mathrm{p}=0.02)$ (Figure 8). Example of MIB-1 staining is shown in Figure $7 \mathrm{~b}$. The median survival of

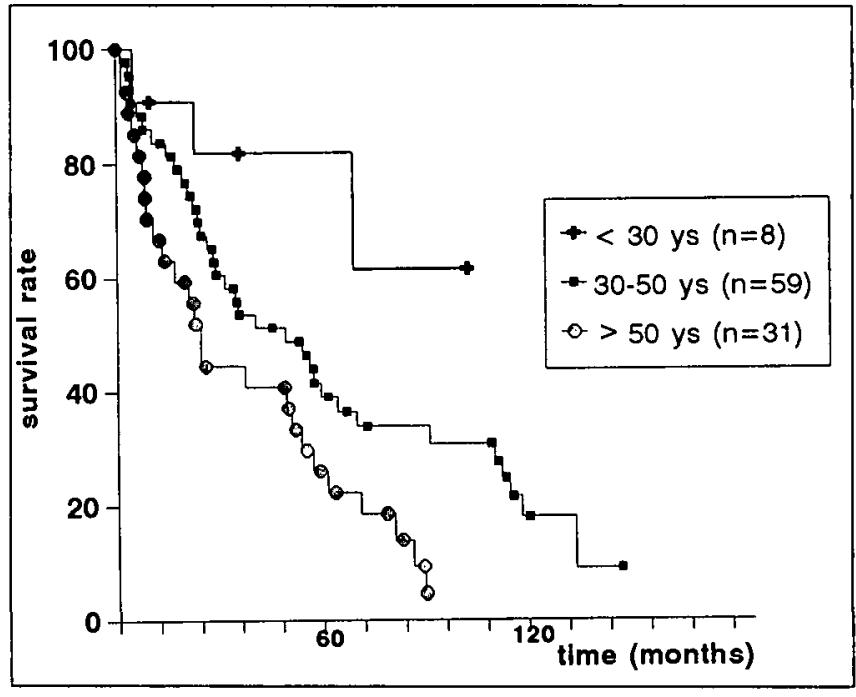

Figure 1: Survival of patients by age $(p=0.0003)$.

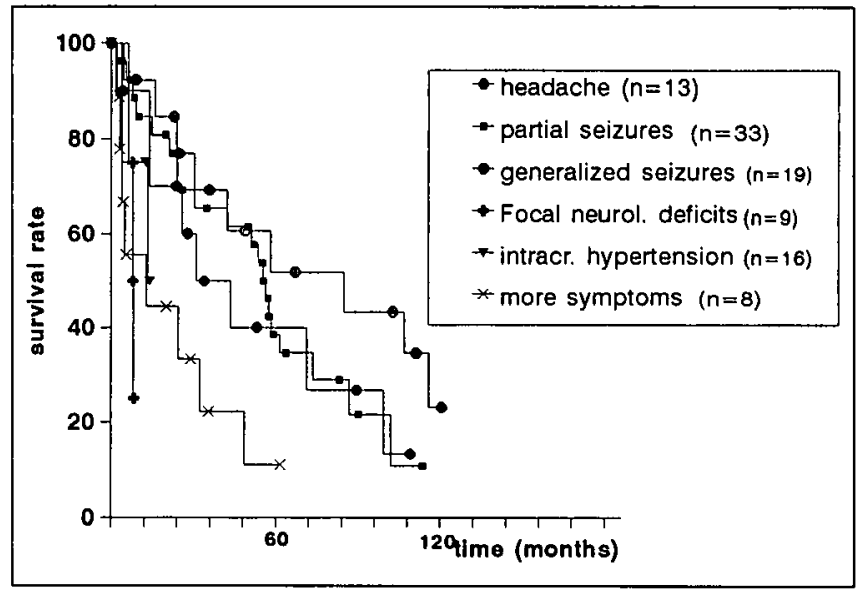

Figure 2: Survival of patients by symptoms at presentation $(p=0.005)$.

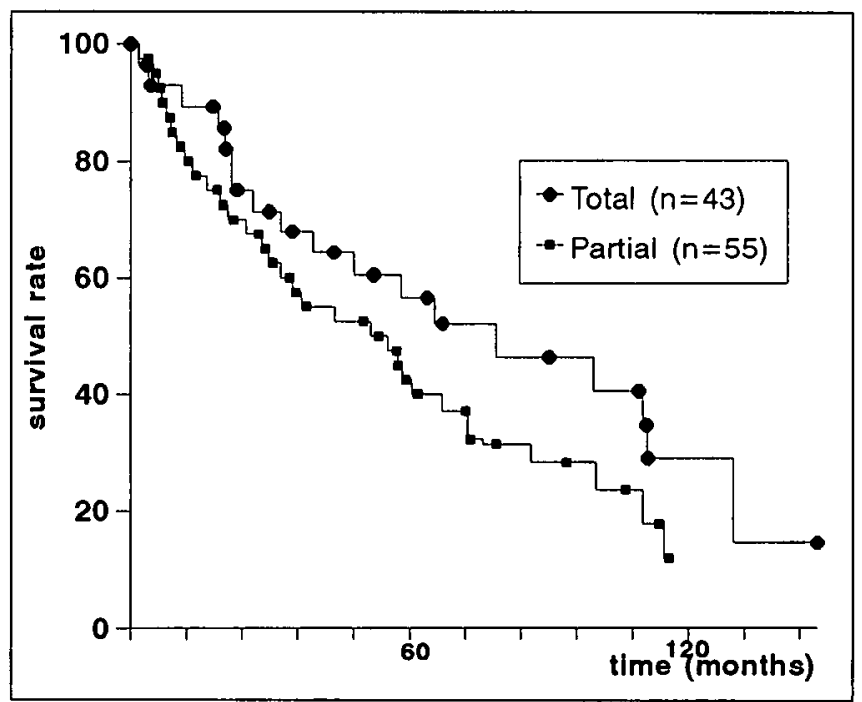

Figure 3: Survival of patients by extent of resection $(p=0.03)$. 


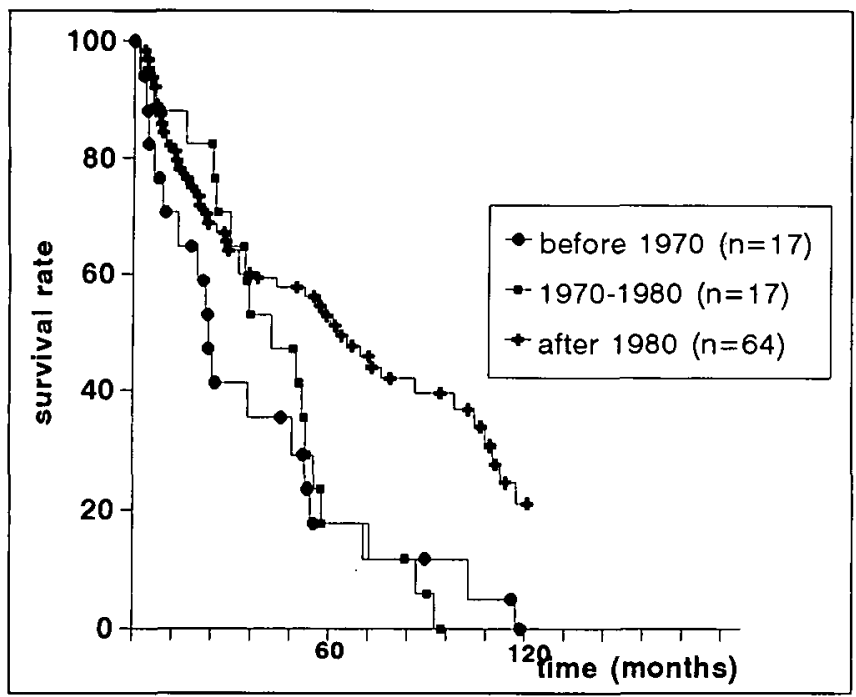

Figure 4: Survival of patients by year of surgery $(p=0.008)$.

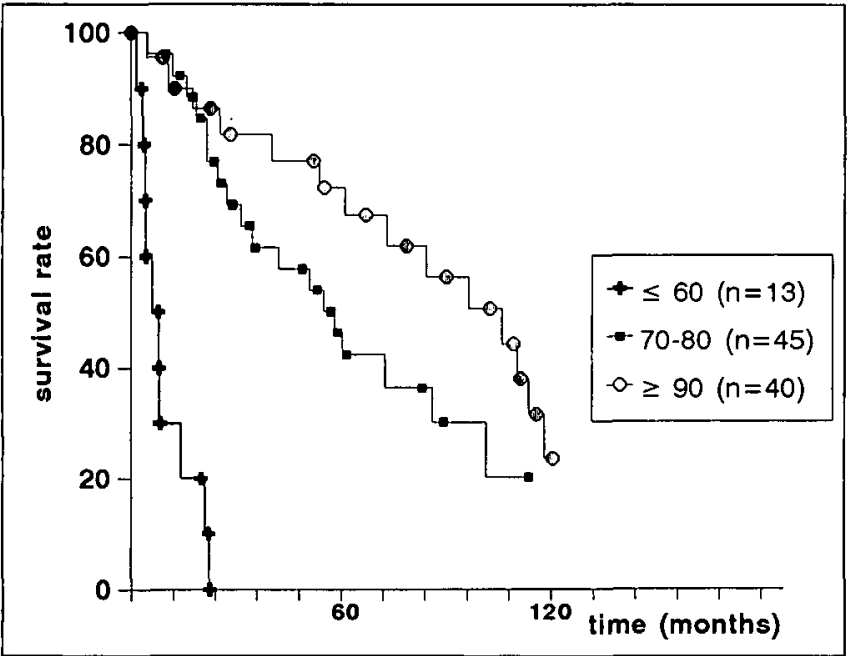

Figure 5: Survival of patients by post-operative Karnofsky score $(p=$ $0.0001)$.

the 44 cases with PCNA LI $\geq 3.5 \%$ was 29 months versus 58 months of the 27 cases with PCNA LI $<3.5 \%(\mathrm{p}=0.02)$.

Radiotherapy: thirty-six patients received post-operative radiotherapy, while 62 did not. The median survival of the two groups were not significantly different: 56 and 57 months, respectively. Radiotherapy after total removal did not affect survival. Patients who underwent partial resection plus radiotherapy showed a trend towards better survival: median survival of 59 months compared to 25 months of patients who underwent partial resection only $(\mathrm{p}=0.11)$. Only 7 patients received chemotherapy. The comparison between this little group and the group that did not receive chemotherapy was not significant $(\mathrm{p}=$ 0.35 ).

After immunostaining for GFAP, the 26 tumors showing the presence of GFOC and/or MG did not differ for survival from GFAP-negative oligodendrogliomas. Similarly, the 20 cases containing tumor astrocytes and regular gemistocytes did not differ from pure oligodendrogliomas.

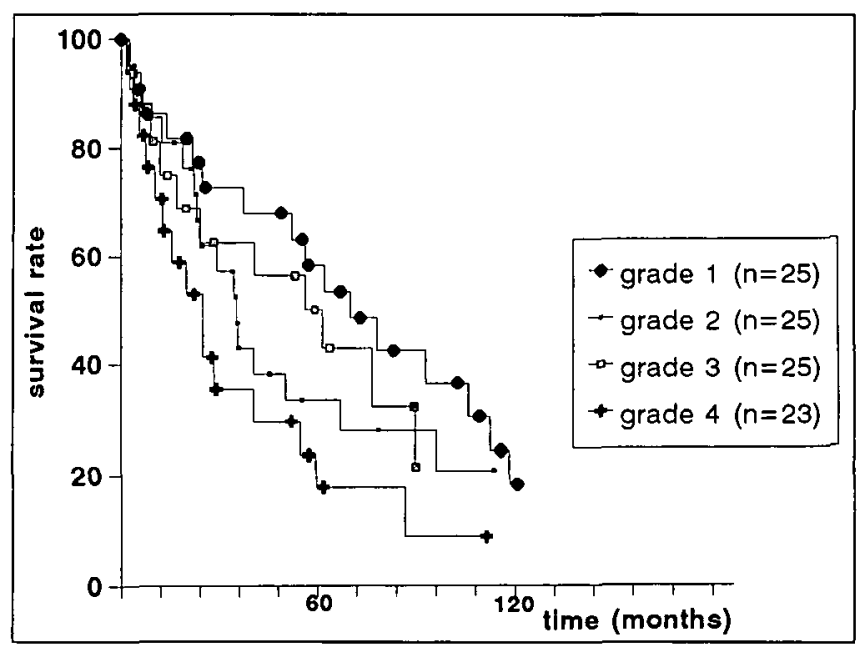

Figure 6: Survival of patients by the St.Anne-Mayo grading system ( $p$ $=$ n.s.).

Only 13 cases showed a positivity for $\mathrm{p} 53$. In 4 cases $>50 \%$ of nuclei were intensely and diffusely positive in the whole specimen, in 2 cases $>50 \%$ of nuclei were weakly and diffusely positive in the whole specimen; in 7 cases nuclear staining was only locally positive and interested $<20 \%$ of nuclei. Out of the 20 cases of oligoastrocytoma only 2 showed a diffuse and irregular positivity. Four of the p53-positive cases, with focal and weak positivity, belonged to the group of grades 1-2. Nine positive tumors were of grade 3-4, representing almost $20 \%$ of tumors of these grades. Positivity for p53 was not significantly associated with survival. In multivariate analysis, the factors associated with survival are indicated in Table 2.

Table 2: Factors Associated with Survival in Multivariate Analysis by Cox Proportional Hazard Method.

\begin{tabular}{ll}
\hline FACTORS ASSOCIATED WITH SURVIVAL IN & \\
MULTIVARIATE ANALYSIS & P value \\
\hline age at surgery (<30 vs. $30-50$ vs. $>50)$ & $\mathrm{p}=0.02$ \\
extent of resection (total vs. partial) & $\mathrm{p}=0.01$ \\
year of surgery (before 1970 vs. $1970-1980$ vs. after 1980$)$ & $\mathrm{p}=0.007$ \\
post-operative Karnofsky score $(\leq 60$ vs. $70-80$ vs. $\geq 90)$ & $\mathrm{p}=0.0001$ \\
MIB-1 LI (MIB-1 LI $<8 \%$ vs. $\geq 8 \%)$ & $\mathrm{p}=0.03$ \\
\hline
\end{tabular}

\section{Discussion}

The survival times in our series, mean $66( \pm 6)$ months and median 51.6 months, are within the ranges found in most of the previous studies, ${ }^{12,15.19}$ but longer survivals have been reported. ${ }^{10,13}$

One of the most important points to be discussed is histology. There is no general agreement in the literature either on the prognostic significance of the different histological factors, on the criteria for recognizing the histological grades, or on the correlation between grade and survival. Some reports, reviewing large series, discussed the problem of prognosis in relation to histological features, but various factors appeared to have a different prognostic significance. For example, pleomorphism was a negative prognostic factor ${ }^{7}$ and, in other series, necrosis was 

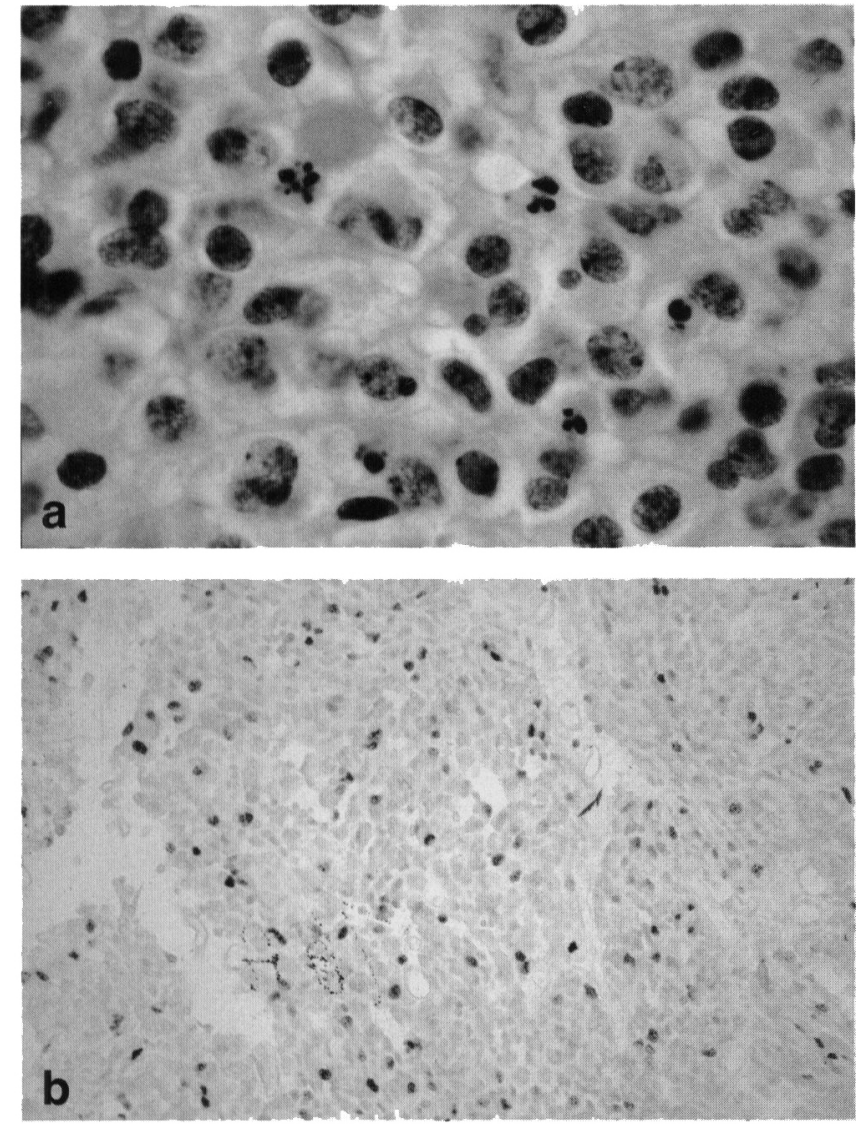

Figure 7: Oligodendrogliomas: a) apoptotic nuclei and bodies, $H \& E$, 1000x; b) high MIB-1 LI in a grade 4 oligodendroglioma, MIB-1, 200x.

associated with shorter survivals ${ }^{11}$ even in multivariate analysis. ${ }^{12,17}$ Mitoses did not represent a prognostic factor ${ }^{11}$ or were prognostic only in multivariate analyses. ${ }^{9,12}$ The criteria proposed by the WHO Classification in order to distinguish the classic from the anaplastic variant of the tumor are important guidelines but they are rather subjective. In older reports, a faster progression of more anaplastic tumors in comparison with well-differentiated ones was not found..$^{28-30}$ Later, a three grade system was proved to have prognostic significance ${ }^{7}$ and recently these results were confirmed in multivariate analysis. ${ }^{9}$ In another recent study ${ }^{10}$ a correlation with survival was found grouping together grade $1+2$ and grade $3+4$, either using Kernohan ${ }^{31}$ or the St. Anne-Mayo system ${ }^{20}$ with a more significant correlation by the former in comparison with the latter. In our series, no statistically significant correlation was found using the four grade system of the St. Anne-Mayo even though, grouping together grades $1+2+3$ against grade 4 , a trend towards a worse survival of the highest grade was observed. It should be emphasized that presence of mitoses was the only parameter, among those employed for the recognition of grades, which was statistically correlated with survival $(\mathrm{p}=0.04)$. Using MI with a cut-off at $0.2 \%$ a better correlation with survival emerged $(p=0.02)$. It is important to note that in oligodendrogliomas there is a wide overlapping of MI between classic and anaplastic variant, identified with the St. Anne-Mayo system. ${ }^{32}$ In this grading system, mitoses are

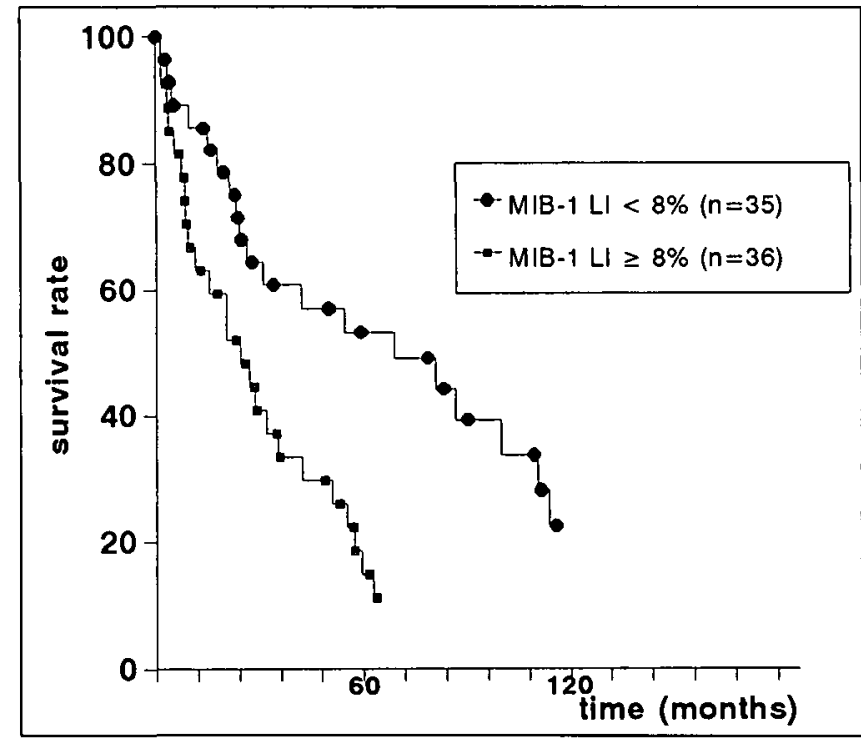

Figure 8: Survival of patients by MIB-I labeling index $(L I)(p=0.02)$.

evaluated as present or absent, regardless of their number, so that one single mitosis may shift the grade of a tumor to the higher one. This can be a bias, because the prognostic significance of one single mitosis may depend on the number of fields counted before finding it. However, using MI with a cutoff at $0.2 \%$ instead of the presence of mitoses in the St. AnneMayo system, the correlation between grades and survival did not significantly change.

The evaluation of AI by counting apoptotic nuclei, either after staining with basic dyes or ISEL-technique, encounters many technical difficulties. ${ }^{33} \mathrm{AI}$ cannot be used directly for prognostic purposes, since it must be discussed in the light of many factors. Many observations suggest that AI can be correlated either with survival or with the proliferative potential of the tumor. For example, in bladder cancer, it is related to mitotic activity and it is not a prognostic factor. ${ }^{34}$ In neuroepithelial tumors, AI was found to correlate weakly with proliferation marker LIs ${ }^{35}$ moreover, even following the variation of $\mathrm{MI}$, it did not correlate with survival. ${ }^{33}$ On the contrary, in the present series AI was found to correlate very weakly with survival $(p=$ 0.05 ). A possible explanation is that AI represents a phenomenon correlated with mitoses. However, both AI and MI lose their significance in multivariate analysis. For MI our results are in agreement with a recent investigation. ${ }^{9}$

The prognostic importance of MIB-1 LI has already been emphasized. ${ }^{9.14}$ In our series it represents a prognostic factor also in multivariate analysis. However, it should be considered that there is a wide overlapping of MIB-1 LI ranges between the classic and the anaplastic variant, as defined by the St. AnneMayo system. Since no significant correlation between grades and survival was found in our study, MIB-1 LI comes out as a very important prognostic factor, adding prognostic information independently from histopathologic grading. PCNA LI is prognostic in univariate analysis, but not in multivariate analysis. This is consistent with the lower reliability of PCNA LI, mainly because of the weak reproducibility of the staining. ${ }^{36.37}$

Oligoastrocytomas were included in this series, as in 
others. ${ }^{4,7.13 .18}$ Oligodendrogliomas containing tumor astrocytes and gemistocytes, independently from the extension of astrocytic areas, did not show any difference in comparison with pure oligodendrogliomas for survival. Considering separately oligodendrogliomas with GFOC and/or MG and GFAP-negative oligodendrogliomas, no difference was observed in survival. It must be stressed that our oligoastrocytomas were selected from a series of oligodendrogliomas and not from a series of astrocytomas with oligodendroglial areas. However, in a large series of mixed oligoastrocytomas whether the oligodendrocytic or astrocytic component was predominant or whether the two components were equally represented, did not significantly affect survival. ${ }^{38}$

Recent experimental observations provide evidence that oligodendrocytes and type 2 astrocytes are derived from an $\mathrm{O}-2 \mathrm{~A}$ progenitor cell which is A2B5-positive. Since astrocytic tumor cells in some mixed oligoastrocytomas showed immunostaining for A2B5, neoplastic transformation of these progenitor cells could give rise to both pure and mixed oligodendrogliomas. ${ }^{39,40}$ More recently, oligodendrogliomas and oligoastrocytomas have been shown to share the same genetic alterations with high incidence: loss of heterozygosity on chromosome 1p and 19q. ${ }^{41,42}$ Oligoastrocytomas showed these alterations in both areas of oligodendroglial and astrocytic differentiation. ${ }^{43}$ These findings suggest the monoclonal origin of the astrocytic and oligodendroglial components of mixed tumors.

In our series p53 accumulation was detected only in 13 cases and it had no prognostic significance. If compared with the frequency of p53 accumulation in other oligodendroglioma series, ${ }^{44.45}$ the rate is quite low (13\%). However, our rate is much closer to that of $\mathrm{p} 53$ mutation, usually point mutation, found in molecular biology studies $(10 \%){ }^{46}$ p53 mutations are more characteristic of astrocytic tumors. ${ }^{47}$

In the present study, age at surgery and total resection are good prognostic factors in both uni- and multivariate analysis, as previous observations proposed. In fact the extent of surgical removal has been identified as a prognostic factor in univariate analysis ${ }^{10,13}$ and in a recent series age appears to be an independent prognostic factor. ${ }^{9}$ The significant difference in survival according to the decades in which surgery has been performed is not surprising. The use of CT-scan, the improvement of neurosurgical techniques and resuscitation care in patients in the last decades seem to be responsible. Furthermore, it should be considered that the earlier diagnosis due to the use of CT-scan in the period following 1976, could have prolonged the total duration of the disease. Generalized seizures and frontal location were correlated with better survival in univariate analysis, as observed respectively in previous studies. ${ }^{8,19}$ However, in our series, Karnofsky status is definitely the most important factor in multivariate analysis.

In the literature, post-operative irradiation has been found either to prolong survival ${ }^{13,19,48}$ or not. ${ }^{8,17}$ Our findings that radiotherapy is ineffective when performed in patients with total removal and responsible for a trend towards longer survival in patients with partial removal are in agreement with previous observations that radiation therapy is useful in patients with partial resection, provided that high doses are given. ${ }^{10}$ In our series no patient was irradiated with $<40 \mathrm{~Gy}$.
Our conclusions are that histology is hardly useful for prognostic purposes and that MIB-1 LI can help in recognizing the malignant variant. Clinical and therapeutic parameters such as age, extent of surgical removal, post-operative Karnofsky status show a clear prognostic value.

\section{ACKNOWLEDGEMENTS}

We thank Dr. Kim Martin (Institute of Psychiatry, Dept. Neuropathology, London) for her precious suggestions and Mrs. Rita Paglino (Dept. Neurosurgery, University of Milan, Milan) for her technical assistance. Supported by CNR.ACRO, Rome and AIRC, Milan.

\section{REFERENCES}

1. Zülch KJ: Brain Tumours. Their Biology and Pathology. 3rd ed. Berlin-Heidelberg-New York-Tokyo: Springer, 1986.

2. Russell DS and Rubinstein LJ. Pathology of Tumours of the Nervous System. 5th ed. London: Amold, 1989.

3. Cairncross JG. and Macdonald DR. Successful chemotherapy for recurrent malignant oligodendroglioma. Ann Neurol 1988; 23: 360-364.

4. Glass J, Hochberg FH, Gruber ML, et al. The treatment of oligodendrogliomas and mixed oligoendroglioma-astrocytomas with PCV chemotherapy. J Neurosurg 1992; 76: 741-745.

5. Kyritsis AP, Yung WKA, Bruner J, Gleason MJ, Levin VA. The treatment of anaplastic oligodendrogliomas and mixed gliomas. Neurosurgery 1993; 32: 365-371.

6. Mason WP, Krol GS, De Angelis LM. Low-grade oligodendroglioma responds to chemotherapy. Neurology 1996; 46: 203207.

7. Smith MT, Ludwig CL, Godfrey AD, Armbrustmacher VW. Grading of oligodendrogliomas. Cancer 1983; 52: 2107-2114.

8. Kros JM, Pieterman $\mathrm{H}$, van Eden CG, Avezaat CJJ Oligodendroglioma: the Rotterdam-Dijkzigt experience. Neurosurgery 1994; 34: 959-966.

9. Kros JM, Hop WCJ, Godschalk JCJ, Krishnadath KK. Prognostic value of the proliferation-related antigen $\mathrm{Ki}-67$ in oligodendrogliomas. Cancer 1996; 78: 1107-1113.

10. Shaw EG, Scheithauer BW, O'Fallon JR, Tazelaar HD, Davis DH. Oligodendrogliomas: the Mayo Clinic experience. J Neurosurg 1992; 76: 428-434.

11. Mørk SJ, Halvorsen TB, Lindegaard K-F, Eide GE. Oligodendroglioma. Histologic evaluation and prognosis. J Neuropathol Exp Neurol 1986; 45: 65-78.

12. Burger PC, Rawlings CE, Cox EB, et al. Clinicopathologic correlations in the oligodendroglioma. Cancer 1987; 59: 1345-1352.

13. Celli P, Nofrone I, Palma L, Cantore G, Fortuna A. Cerebral oligodendroglioma: prognostic factors and life history. Neurosurgery 1994; 35: 1018-1035.

14. Coons SW and Johnson PC. MIB-1/Ki-67 labeling index predicts patient survival for oligodendroglial tumors. J Neuropathol Exp Neurol 1995; 24: 9-12.

15. Heegard S, Sommer HM, Broholm H, Broendstrup O. Proliferating cell nuclear antigen and Ki-67 immunohistochemistry of oligodendrogliomas with special reference to prognosis. Cancer 1995; 76: $1809-1813$.

16. Kleihues P, Burger PC, Scheithauer BW. WHO. Histological Typing of Tumours of the Central Nervous System. 2nd ed. Berlin, Heidelberg, New York, etc. Springer, 1993, 19.

17. Bullard DE, Rawlings CE, Phillips B, et al. Oligodendroglioma. An analysis of the value of radiation therapy. Cancer $1987 ; 60$ : 2179-2188.

18. Nijjar TS, Simpson WJ, Gadalla T, McCartney M. Oligodendroglioma. The Princess Margaret Hospital Experience (19581984). Cancer 1993; 71: 4002-4006.

19. Mørk SJ, Lindergaard K-F, Halvorsen TB, et al. Oligodendroglioma: incidence and biological behavior in a defined population. J Neurosurg 1985; 63: 881-889. 
20. Daumas-Duport C, Scheithauer BW, O'Fallon J, Kelly P. Grading of astrocytomas: a simple and reproducible grading method. Cancer 1988; 62: 2152-2165.

21. Migheli A, Cavalla P, Marino S, Schiffer D: A study of apoptosis in normal and pathologic nervous tissue after in situ end-labeling of DNA strand breaks. J Neuropathol Exp Neurol 1994; 53: 606-616.

22. Herpers MJHM and Budka $H$. Glial fibrillary acidic protein (GFAP) in oligodendroglial tumors: gliofibrillary oligodendroglioma and transitional oligoastrocytoma as subtypes of oligodendroglioma. Acta Neuropathol 1984; 64: 265-272.

23. Schiffer D, Chiò A, Giordana MT, Pezzulo T, Vigliani MC. Proliferating cell nuclear antigen expression in brain tumors, and its prognostic role in ependymomas: an immunohistochemical study. Acta Neuropathol 1993; 85: 495-502.

24. Kaplan EL and Meier P. Non-parametric estimation from incomplete observation. J Am Stat Assoc 1958; 53: 457-481.

25. Segal MR. Regression trees for censored data. Biometrics 1988; 44: $35-47$

26. Peto R, Pike MG, Armitage $P$, et al. Design and analysis of randomized clinical trials requiring prolonged observation of each patient: analysis and examples. Br J Cancer 1977; 35: 1-39.

27. Cox DR. Regression models and life tables. J R Stat Soc 1972; B34: $187-220$.

28. Earnest F, Kernohan JW, Craig WMcK. Oligodendrogliomas: a review of two hundred cases. Arch Neurol Psychiat 1950; 63: 964-976.

29. Kernohan JW. Oligodendrogliomas. In: Minckler J, ed. Pathology of the Nervous System. Vol 2, New York: Mc Graw-Hill, 1971: 1993-2007.

30. Weir B, Elvidge AR. Oligodendrogliomas: an analysis of 60 cases. J Neurosurg 1968; 29: 500-505.

31. Kernohan JW, Mabon RF, Svien HJ, Adson AW. A simplified classification of the gliomas. Proc Staff Meet Mayo Clinic 1949; 24: $71-75$.

32. Schiffer D, Cavalla P, Pilkington GJ. Proliferative properties of malignant brain tumors. In: Mikkelsen T, Bjerkvig R, Laerum O and Rosemblum ML, eds. Brain Tumor Invasion: Biological, Clinical and Therapeutic considerations. John Wiley and Sons Inc, 1996.

33. Schiffer D, Cavalla P, Migheli A, Chiò A, Giordana MT. Apoptosis and cell proliferation in neuroepithelial tumors. Neurosci Lett 1995; 195: 81-84.

34. Lipponen PK and Aaltomaa S. Apoptosis in bladder cancer as related to standard prognostic factors and prognosis. J Pathol 1994; 173: 333-339.
35. Ellison DW, Steart PV, Gatter KC, Weller RO. Apoptosis in cerebral astrocytic tumours and its relationship to expression of the bcl-2 and p53 proteins. Neuropathol Appl Neurobiol 1995; 21: 352-361.

36. Khoshyomn S, Maier H, Morimura T, Kitz K, Budka H. Immunostaining for proliferating cell nuclear antigen: its role in determination of proliferation in routinely processed human brain tumor specimens. Acta Neuropathol 1993; 86: 582-589.

37. Karamitopoulou E, Perentes E, Melachrinou M, Maraziotis T. Proliferating cell nuclear antigen immunoreactivity in human central nervous system neoplasms. Acta Neuropathol 1993; 85: 316-322.

38. Shaw EG, Scheithauer BW, O'Fallon JR, Davis DH. Mixed oligoastrocytomas: a survival and prognostic factor analysis. Neurosurgery $1994 ; 34: 577-582$.

39. de la Monte SM. Uniform lineage of oligodendrogliomas. Am J Pathol 1989; 135: 529-540.

40. Bishop M and de la Monte SM. Dual lineage of astrocytomas. Am J Pathol 1989; 135: 517-527.

41. von Diemling A, Louis DN, von Ammon K, et al. Evidence for a tumor suppressor gene on chromosome $19 \mathrm{q}$ associated with human astrocytoma, oligodendroglioma and mixed glioma. Cancer Res 1992; 52: 4277-4279.

42. Reifenberger J, Reifenberger G, Liu L, et al. Molecular genetic analysis of oligodendroglial tumors shows preferential allelic deletions on 19q and 1p. Am J Path 1994; 145: 1175-1189.

43. Kraus JA, Koopman J, Kaskel P, et al. Shared allelic losses on chromosomes $1 p$ and $19 q$ suggest a common origin of oligodendroglioma and oligoastrocytoma. J Neuropathol Exp Neurol 1995; 54: 91-95.

44. Kros JM, Godschalk JJCJ, Krishnadath KK, van Eden CG. Expression of p53 in oligodendrogliomas. J Pathol 1993; 171: 285-290.

45. Pavelic J, Hlavka V, Poljak M, Gale N, Pavelic K. p53 immunoreactivity in oligodendrogliomas. J Neuro-Oncol 1994; 22: 1-6.

46. Wu JK, Zhen Y, Darras BT. Frequency of p53 tumor suppressor gene mutations in human primary brain tumors. Neurosurgery 1993; 33: 824-831.

47. Louis DN, von Deimling A, Chung RY, et al. Comparative study of p53 gene and protein alterations in human astrocytic tumours. J Neuropathol Exp Neurol 1993; 52: 31-38.

48. Wallner KE, Gonzales M, Sheline GE. Treatment of oligodendrogliomas with or without postoperative irradiation. J Neurosurg 1988; 68: 684-688. 